\title{
End-tidal capnography monitoring in infants ventilated on the neonatal intensive care unit
}

\author{
Emma Williams $\mathbb{I}^{1,2} \cdot$ Theodore Dassios $\mathbb{C}^{1,3} \cdot$ Niamh $^{\prime}$ Reilly $^{1} \cdot$ Alison Walsh ${ }^{1} \cdot$ Anne Greenough $\mathbb{D}^{1,2,4}$
}

Received: 12 August 2020 / Revised: 22 December 2020 / Accepted: 28 January 2021 / Published online: 1 March 2021

(c) The Author(s) 2021. This article is published with open access, corrected publication 2021

\begin{abstract}
Objective To assess whether end-tidal capnography $\left(\mathrm{EtCO}_{2}\right)$ monitoring reduced the magnitude of difference in carbon dioxide $\left(\mathrm{CO}_{2}\right)$ levels and the number of blood gases in ventilated infants.

Study design A case-control study of a prospective cohort $(n=36)$ with capnography monitoring and matched historical controls $(n=36)$.

Result The infants had a median gestational age of 31.6 weeks. A reduction in the highest $\mathrm{CO}_{2}$ level on day 1 after birth was observed after the introduction of $\mathrm{EtCO}_{2}$ monitoring $(p=0.043)$. There was also a reduction in the magnitude of difference in $\mathrm{CO}_{2}$ levels on days $1(p=0.002)$ and $4(p=0.049)$ after birth. There was no significant difference in the number of blood gases.

Conclusion Continuous end-tidal capnography monitoring in ventilated infants was associated with a reduction in the degree of the magnitude of difference in $\mathrm{CO}_{2}$ levels and highest level of $\mathrm{CO}_{2}$ on the first day after birth.
\end{abstract}

\section{Introduction}

Mechanical ventilation can be lifesaving for neonates, but long-term complications are increased in infants who have suffered abnormalities in carbon dioxide $\left(\mathrm{CO}_{2}\right)$ levels. Disturbances in cerebral blood flow caused by the magnitude of difference in $\mathrm{CO}_{2}$ levels and abnormalities in $\mathrm{CO}_{2}$ levels can lead to intraventricular haemorrhage (IVH) and periventricular leukomalacia (PVL) and subsequent cerebral injury $[1,2]$. Furthermore, outcomes of term-born neonates exposed to high $\mathrm{CO}_{2}$ variability during therapeutic hypothermia have been associated with adverse

Anne Greenough

anne.greenough@kcl.ac.uk

1 Department of Women and Children's Health, School of Life Course Sciences, Faculty of Life Sciences and Medicine, King's College London, London, UK

2 The Asthma UK Centre for Allergic Mechanisms in Asthma, King's College London, London, UK

3 Neonatal Intensive Care Unit, King's College Hospital NHS Foundation Trust, London, UK

4 NIHR Biomedical Research Centre based at Guy's and St Thomas' NHS Foundation Trust and King's College London, London, UK neurodevelopment at follow up [3]. The recent European Consensus Guidelines recommend that clinicians should avoid abnormal levels of $\mathrm{CO}_{2}$ by regular or continuous assessment of $\mathrm{CO}_{2}$ levels [4].

The current gold standard for monitoring $\mathrm{CO}_{2}$ levels in newborn infants is by arterial blood gas analysis [5]. This is the most accurate measurement of $\mathrm{CO}_{2}$ levels, however, it is not without complications [6]. Indwelling catheters in neonates can be associated with an increased risk of infection and thrombosis [7]. Frequent blood sampling can also be painful for infants when there is no indwelling arterial catheter. MRI studies have found that early exposure to pain stress in preterm infants is associated with reduced white matter and subcortical brain matter maturation [8]. Follow up of extremely preterm infants exposed to multiple heel prick tests in the neonatal period has shown that this can result in hyperalgesia and increased sensitivity to painful stimuli $[9,10]$. Repeated blood sampling in neonates can lead to iatrogenic anaemia and the requirement for multiple blood transfusions, which are not without risks [11-13]. The Canadian Paediatric Society, Foetus and Newborn Committee recommend non-invasive $\mathrm{CO}_{2}$ monitoring for ventilated, preterm infants to minimise blood loss and the need for multiple transfusions [14].

Non-invasive end-tidal carbon dioxide monitoring by capnography is an alternative method of assessing $\mathrm{CO}_{2}$ 
levels. Capnography assesses breath by breath the exhaled carbon dioxide in real time and gives a continuous waveform together with the end-tidal $\mathrm{CO}_{2}\left(\mathrm{EtCO}_{2}\right)$ level [15]. Use of capnography may, therefore, reduce large magnitude of difference in $\mathrm{CO}_{2}$ levels. Indeed, one study found the use of continuous capnography during the resuscitation of mechanically ventilated term lambs with meconium aspiration syndrome reduced the degree of the magnitude of difference in $\mathrm{CO}_{2}$ levels [16]. Mainstream or sidestream capnography can be used. We recently reported on the performance of a novel microstream sidestream capnography device in ventilated newborns and found a good correlation of the results of that device with the gold standard mainstream capnograph [17].

We hypothesised that the introduction of sidestream capnography would reduce the magnitude of difference in $\mathrm{CO}_{2}$ levels in mechanically ventilated newborns in the first week after birth and that the number of blood samples would be reduced. We also aimed to determine whether use of sidestream capnography was associated with a reduction in severe intraventricular haemorrhage.

\section{Subjects and methods}

The study was conducted on the neonatal intensive care unit at King's College Hospital NHS Foundation Trust $(\mathrm{KCH})$, London UK. Data were collected from a retrospective cohort of ventilated infants (historical controls) cared for in the NICU between 01/01/2017 and 01/01/2019, prior to the addition of end-tidal $\mathrm{CO}_{2}$ monitoring. Prospective data were collected from a cohort of ventilated infants in whom endtidal $\mathrm{CO}_{2}$ monitoring was used from 01/01/2019 to 01/07/ 2020. Data were collected from 200 consecutively born infants admitted to the neonatal intensive care unit from 1/1/ 17 to $1 / 1 / 19,36$ infants from this sample were matched individually for gestational age and birth weight with the 36 infants prospectively recruited. The first infant that fulfilled the matching criteria in reverse chronological order was selected as a matched control. Approval for the study was given by the London (Camden \& King's Cross) Research Ethics Committee (REC reference: 18/LO/1602). Written informed consent was given by parents for their infants to take part in the prospective study. The retrospective data collection was registered with the clinical governance department of King's College Hospital NHS foundation trust for retrospective use of routinely recorded data on the medical and nursing charts. No minimum number of days of invasive ventilation was required to be included into the study. Infants without full $\mathrm{CO}_{2}$ data were excluded as were infants that were not receiving conventional mechanical ventilation.
Infants in both cohorts were supported by volumetargeted or pressure-controlled time-cycled conventional ventilation using the SLE6000 neonatal ventilator (SLE, Croydon, UK). Infants were invasively ventilated using either volume-targeted or pressure-controlled time-cycled modes, which included assist control ventilation, synchronized intermittent mandatory ventilation or conventional mechanical ventilation. If receiving volume-targeting modes, initial targeted tidal volumes (TTV) were set at $5 \mathrm{ml} / \mathrm{kg}$ with peak inspiratory pressure maximum $\left(\mathrm{PIP}_{\max }\right)$ at $20-25 \mathrm{cmH}_{2} \mathrm{O}, \mathrm{PIP}_{\max }$ was adjusted to $5 \mathrm{cmH}_{2} \mathrm{O}$ above what was required to achieve the TTV according to observation of chest movement and blood gas analysis. The positive end-expiratory pressure (PEEP) was set at $5 \mathrm{cmH}_{2} \mathrm{O}$. Routine clinical practice was to adjust the ventilation settings to achieve target blood gases initially of $\mathrm{pH}$ 7.35-7.45 and $\mathrm{PaCO}_{2}$ between 4.5 and $7 \mathrm{kPa}$ in the first week after birth. As per unit policy, infants were intubated with a Cole's shouldered endotracheal tube which minimizes leak [18]. In the prospective cohort, the Microstream sidestream filterline $\mathrm{H}$ set sidestream capnography sample line (Phillips Medical Systems, Oridion Medical Ltd) was fitted into the ventilator circuit between the ventilator tubing and the endotracheal tube. The sample line adaptor had a deadspace of less than $0.5 \mathrm{mls}$ and a weight of $3.8 \mathrm{~g}$. The sample line connected to the MicroPod, an external $\mathrm{EtCO}_{2}$ module, containing the $\mathrm{CO}_{2}$ nondispersive infrared spectroscopy sensor. Gas was sampled at the proximal end of the endotracheal tube at a rate of $50 \mathrm{mls} /$ minute to the MicroPod. The module performed automatic adjustment for the changes in ambient temperature. A continuous timebased capnography waveform and $\mathrm{EtCO}_{2}$ value was displayed on the ventilator monitor.

Arterial or capillary blood gas samples in both cohorts were taken according to the clinical need of the infant and decided by the clinicians [19]. The clinicians were not blinded to the continuous end-tidal $\mathrm{CO}_{2}$ monitoring which was displayed on the ventilator screen for the prospective cohort of infants. Continuous end-tidal $\mathrm{CO}_{2}$ monitoring was introduced as an adjunct monitoring tool and clinical staff were not instructed to change their clinical practice on the basis of end-tidal capnography alone. The results of $\mathrm{PCO}_{2}$ levels and the timings of blood samples were documented on the hourly nursing observation charts. The blood gas analyser used was the ABL90 FLEX PLUS analyzer (Radiometer UK Ltd.) Our outcomes included the highest and lowest $\mathrm{PCO}_{2}$ level and the degree of the magnitude of difference in $\mathrm{CO}_{2}$ levels of $\mathrm{PCO}_{2}$ levels (delta $\mathrm{PCO}_{2}$ ) on each day of invasive ventilation in the first week after birth. Delta $\mathrm{PCO}_{2}$ was calculated from blood gases values as the difference between the highest and lowest $\mathrm{PCO}_{2}$ values on each day. 
The following data were collected from the medical and nursing notes: gestational age at birth, birth weight, gender, mode of ventilation, number of blood gas samples taken per day, the highest and lowest blood gas $\mathrm{PCO}_{2}$ levels per day and severe (grades 3 or 4) IVH. Data regarding the number of blood gases and levels of $\mathrm{PCO}_{2}$ for the prospective cohort of infants were only included if the sidestream end-tidal $\mathrm{CO}_{2}$ device was incorporated for the whole duration of each $24-\mathrm{h}$ period of invasive ventilation so that consistent exposure to $\mathrm{EtCO}_{2}$ could be assessed.

\section{Analysis}

The data were tested for normality using the Kolmogorov-Smirnov test and found not to be normally distributed. Differences between the matched pairs of infants with and without end-tidal $\mathrm{CO}_{2}$ monitoring, therefore, were assessed for statistical significance using the Wilcoxon paired rank sum test. Statistical analyses were undertaken using the SPSS software version 25.0 (SPSS Inc., Chicago IL).

\section{Results}

Seventy-two infants were included in the study, 36 in the prospective group with end-tidal $\mathrm{CO}_{2}$ monitoring and 36 in the historical control group. Not all the infants remained ventilated for all 7 days (Table 1). The infants in the control group had a median gestational age of 31.6 (26.2-38.1) weeks and a birthweight of 1.51 (0.90-2.91) $\mathrm{kg}$. The infants in the prospective cohort had a median gestational age of 31.6 (25.9-38.2) weeks and a birthweight of $1.35(0.83-3.08) \mathrm{kg}$. There was no significant difference in the modes of ventilation used in the two cohorts $(p=1.0)$.

There was a significant reduction in the highest $\mathrm{PCO}_{2}$ measured on arterial or capillary blood gases in the prospective group compared to the historical control group on day 1 after birth [5.8 (5.3-6.7) $\mathrm{kPa}$ versus 7.7 (6.0-9.2) $\mathrm{kPa}$; $p=0.043$. There was also a significant reduction in the delta $\mathrm{PCO}_{2}$ levels on day 1 after birth $[1.4(1.1-3.0) \mathrm{kPa}$ versus $3.7(1.8-6.2) \mathrm{kPa} ; p=0.002]$ and on day $4[1.5$ $(0.5-2.6) \mathrm{kPa}$ versus $1.1(0.6-1.5) \mathrm{kPa} ; p=0.049]$.

No significant difference was observed in the number of blood gases between those with and those without $\mathrm{EtCO}_{2}$ monitoring (Table 1). There was no reduction in severe (grades 3 or 4 ) intraventricular haemorrhage within the prospective cohort compared to the retrospective controls [2 $(10.5 \%)$ versus $2(10.5 \%) ; p=1.0]$ or in the most prematurely born infants and at highest risk of IVH (Table 2).

\section{Discussion}

Continuous, real-time sidestream capnography was associated with a reduction in the degree of the magnitude of difference in $\mathrm{CO}_{2}$ levels and highest level of carbon dioxide on the first day after birth in mechanically ventilated infants.

We have reported that abnormal levels of carbon dioxide, including large magnitude of difference in $\mathrm{CO}_{2}$ levels during resuscitation contribute to IVH development [20]. A previous retrospective study reported the maximum $\mathrm{PCO}_{2}$ during the first 72 hours after birth was a dose-dependent predictor of severe IVH development [21]. Continuous monitoring of $\mathrm{EtCO}_{2}$ may, therefore, have the potential to reduce the complications associated with abnormal $\mathrm{PCO}_{2}$ levels. The low rates of IVH and the lack of significant difference in IVH rates between the two groups in our study may reflect that despite tighter control of carbon dioxide levels in the prospective cohort, the median $\mathrm{PCO}_{2}$ values in both cohorts were still maintained within the recommended range for preterm infants on invasive ventilation [22]. We appreciate that our sample size, particularly in the sub-analysis, did not allow us to robustly assess whether the monitoring had an impact on the incidence of IVH, but this was not our primary objective.

A reduction in the magnitude of difference in $\mathrm{CO}_{2}$ levels of $\mathrm{PCO}_{2}$ levels on day 1 after birth in the whole prospective cohort and on day 4 in the infants is in agreement with a previous study using distal $\mathrm{EtCO}_{2}$ monitoring [23]. That study, however, had a primary outcome of the time spent within a predefined range of $\mathrm{PCO}_{2}$ rather than the magnitude of difference in $\mathrm{CO}_{2}$ levels of $\mathrm{PCO}_{2}$ values. Distal $\mathrm{EtCO}_{2}$ monitoring, however, is not widely used in the neonatal population.

In a retrospective study in a paediatric intensive care unit, a reduction in the total number of blood gas analyses was found, following the introduction of continuous sidestream capnography [24]. The change in clinician behaviour, however, was over a 3-year period [24]. The introduction of transcutaneous $\mathrm{CO}_{2}$ monitoring in ventilated infants, despite only showing a moderate agreement with $\mathrm{PCO}_{2}$ values and no decrease in rates of IVH, was associated with a reduction in the frequency of blood gas sampling [25], with the reduction being more pronounced in infants receiving high frequency oscillatory ventilation (HFOV). In this study, there was no reduction in the frequency of blood gas sampling following the introduction of capnography monitoring. It may be noted that our study period was too short for an effect on behaviour to have occurred or the display of continuous $\mathrm{EtCO}_{2}$ levels may have prompted clinicians to undertake confirmatory blood gases if extremes were noted and hence keeping infants within a narrower range of $\mathrm{PCO}_{2}$.

There has been some scepticism amongst clinicians regarding the use of capnography in neonates [26] due to their small tidal volumes and rapid respiratory rates [27]. 
Table 1 Demographics and daily results for the full cohort of infants.

\begin{tabular}{|c|c|c|c|}
\hline & $\begin{array}{l}\text { Retrospective } \\
(n=36)\end{array}$ & $\begin{array}{l}\text { Prospective } \\
(n=36)\end{array}$ & $p$ value \\
\hline Gestational age (weeks) & $31.6(26.2-38.1)$ & $31.6(25.9-38.2)$ & 0.327 \\
\hline Birthweight (kg) & $1.51(0.90-2.91)$ & $1.35(0.83-3.08)$ & 0.177 \\
\hline Male gender & $19(52.8)$ & $18(52.9)$ & 1.000 \\
\hline Antenatal steroids (Y) & $23(63.9)$ & $22(69.4)$ & 0.687 \\
\hline MgSO4 (Y) & $13(43.3)$ & $14(38.9)$ & 1.000 \\
\hline Postnatal surfactant $(\mathrm{Y})$ & $23(65.7)$ & $21(60.0)$ & 1.000 \\
\hline BPD 36 weeks (Y) & $14(40.0)$ & $15(42.9)$ & 1.000 \\
\hline Home oxygen (Y) & $4(12.1)$ & $6(16.7)$ & 0.375 \\
\hline IVH (grades 3-4) & $2(5.6)$ & $1(2.9)$ & 1.000 \\
\hline Survival to discharge $(\mathrm{Y})$ & $32(94.1)$ & $30(93.8)$ & 1.000 \\
\hline \multicolumn{4}{|l|}{ Day $1(n=32)$} \\
\hline Highest $\mathrm{PCO}_{2} \mathrm{kPa}$ & $7.7(6.0-9.2)$ & $5.8(5.3-6.7)$ & 0.043 \\
\hline Lowest $\mathrm{PCO}_{2} \mathrm{kPa}$ & $4.5(3.4-5.9)$ & $4.3(3.6-4.8)$ & 0.898 \\
\hline Delta $\mathrm{PCO}_{2} \mathrm{kPa}$ & $3.7(1.8-6.2)$ & $1.4(1.1-3.0)$ & 0.002 \\
\hline Number blood gases & $3.5(3.0-6.0)$ & $3.0(2.0-4.0)$ & 0.249 \\
\hline \multicolumn{4}{|l|}{ Day $2(n=23)$} \\
\hline Highest $\mathrm{PCO}_{2} \mathrm{kPa}$ & $6.3(5.4-7.3)$ & $5.6(5.0-6.9)$ & 0.910 \\
\hline Lowest $\mathrm{PCO}_{2} \mathrm{kPa}$ & $4.5(3.6-5.0)$ & $4.3(3.8-5.1)$ & 0.266 \\
\hline Delta $\mathrm{PCO}_{2} \mathrm{kPa}$ & $2.0(1.6-2.8)$ & $1.4(0.6-2.7)$ & 0.197 \\
\hline Number blood gases & $5.0(4.0-7.0)$ & $4.0(2.5-6.5)$ & 0.225 \\
\hline \multicolumn{4}{|l|}{ Day $3(n=20)$} \\
\hline Highest $\mathrm{PCO}_{2} \mathrm{kPa}$ & $5.7(5.3-6.8)$ & $6.7(5.6-7.5)$ & 0.014 \\
\hline Lowest $\mathrm{PCO}_{2} \mathrm{kPa}$ & $4.7(4.1-5.3)$ & $4.7(4.0-5.1)$ & 0.195 \\
\hline Delta $\mathrm{PCO}_{2} \mathrm{kPa}$ & $1.1(0.8-2.8)$ & $2.0(1.0-3.0)$ & 0.844 \\
\hline Number blood gases & $5.0(2.3-6.0)$ & $4.0(4.0-7.0)$ & 0.293 \\
\hline \multicolumn{4}{|l|}{ Day $4(n=15)$} \\
\hline Highest $\mathrm{PCO}_{2} \mathrm{kPa}$ & $6.3(5.6-6.5)$ & $5.8(5.1-6.7)$ & 0.574 \\
\hline Lowest $\mathrm{PCO}_{2} \mathrm{kPa}$ & $4.6(3.8-5.2)$ & $4.8(4.5-5.2)$ & 0.102 \\
\hline Delta $\mathrm{PCO}_{2} \mathrm{kPa}$ & $1.5(0.5-2.6)$ & $1.1(0.6-1.5)$ & 0.049 \\
\hline Number blood gases & $5.0(4.0-6.0)$ & $5.0(4.0-5.0)$ & 0.449 \\
\hline \multicolumn{4}{|l|}{ Day $5(n=13)$} \\
\hline Highest $\mathrm{PCO}_{2} \mathrm{kPa}$ & $6.7(5.9-7.6)$ & $5.9(5.2-6.8)$ & 1.000 \\
\hline Lowest $\mathrm{PCO}_{2} \mathrm{kPa}$ & $5.0(4.4-5.4)$ & $5.9(4.1-5.6)$ & 0.484 \\
\hline Delta $\mathrm{PCO}_{2} \mathrm{kPa}$ & $1.7(0.9-2.7)$ & $1.0(0.7-3.2)$ & 1.000 \\
\hline Number blood gases & $5.0(2.5-7.0)$ & $5.0(3.0-5.8)$ & 0.938 \\
\hline \multicolumn{4}{|l|}{ Day $6(n=11)$} \\
\hline Highest $\mathrm{PCO}_{2} \mathrm{kPa}$ & $6.5(5.8-7.3)$ & $6.2(5.5-7.4)$ & 0.250 \\
\hline Lowest $\mathrm{PCO}_{2} \mathrm{kPa}$ & $5.3(4.8-6.0)$ & $5.5(4.7-6.0)$ & 1.000 \\
\hline Delta $\mathrm{PCO}_{2} \mathrm{kPa}$ & $1.0(0.5-2.6)$ & $1.0(0.5-2.0)$ & 0.875 \\
\hline Number blood gases & $4.0(3.0-6.0)$ & $4.5(1.8-6.0)$ & 0.250 \\
\hline \multicolumn{4}{|l|}{ Day $7(n=7)$} \\
\hline Highest $\mathrm{PCO}_{2} \mathrm{kPa}$ & $7.6(7.3-8.0)$ & $7.0(6.4-8.2)$ & 0.875 \\
\hline Lowest $\mathrm{PCO}_{2} \mathrm{kPa}$ & $5.8(5.5-6.0)$ & $6.0(4.7-6.5)$ & 0.875 \\
\hline Delta $\mathrm{PCO}_{2} \mathrm{kPa}$ & $1.7(1.2-2.0)$ & $1.1(0.6-1.7)$ & 0.875 \\
\hline Number blood gases & $5.0(3.0-6.0)$ & $5.0(3.0-7.3)$ & 0.125 \\
\hline
\end{tabular}

$1 \mathrm{kPa}=7.5 \mathrm{mmHg}$.

Data are presented as median (IQR) or $n(\%)$. 
Table 2 Demographics and daily results for the subgroup of very premature infants. Data are presented as median (IQR) or $n(\%)$.

\begin{tabular}{|c|c|c|c|}
\hline$<32$ weeks $(n=38)$ & Retrospective & Prospective & $p$ value \\
\hline Gestational age (weeks) & $26.3(25.3-30.0)$ & $26.1(25.0-30.0)$ & \\
\hline Birthweight $(\mathrm{kg})$ & $0.93(0.72-1.29)$ & $0.88(0.63-1.06)$ & \\
\hline IVH (Gr3/4) & $2(10.5)$ & $2(10.5)$ & 1.000 \\
\hline \multicolumn{4}{|l|}{ Day 1} \\
\hline Highest $\mathrm{PCO}_{2} \mathrm{kPa}$ & $7.9(4.6-8.8)$ & $6.1(5.3-6.9)$ & 0.240 \\
\hline Lowest $\mathrm{PCO}_{2} \mathrm{kPa}$ & $4.7(3.8-6.2)$ & $4.6(4.0-5.2)$ & 0.938 \\
\hline Delta $\mathrm{PCO}_{2} \mathrm{kPa}$ & $3.1(1.3-4.8)$ & $1.4(1.2-2.9)$ & 0.020 \\
\hline Number blood gases & $3.0(3.0-6.0)$ & $3.0(2.0-3.3)$ & 0.438 \\
\hline \multicolumn{4}{|l|}{ Day 2} \\
\hline Highest $\mathrm{PCO}_{2} \mathrm{kPa}$ & $6.7(5.3-7.7)$ & $5.6(5.1-7.1)$ & 0.375 \\
\hline Lowest $\mathrm{PCO}_{2} \mathrm{kPa}$ & $5.0(3.6-5.3)$ & $4.6(3.3-5.3)$ & 0.625 \\
\hline Delta $\mathrm{PCO}_{2} \mathrm{kPa}$ & $2.2(3.3-6.8)$ & $1.2(0.8-3.0)$ & 0.875 \\
\hline Number blood gases & $5.0(3.3-6.8)$ & $4.5(3.3-6.0)$ & 0.625 \\
\hline \multicolumn{4}{|l|}{ Day 3} \\
\hline Lowest $\mathrm{PCO}_{2} \mathrm{kPa}$ & $6.0(5.6-7.5)$ & $7.0(5.7-8.0)$ & 0.125 \\
\hline Delta $\mathrm{PCO}_{2} \mathrm{kPa}$ & $5.2(4.5-5.4)$ & $5.0(4.3-5.7)$ & 0.875 \\
\hline Highest $\mathrm{PCO}_{2} \mathrm{kPa}$ & $1.0(0.8-2.9)$ & $2.3(0.9-3.8)$ & 0.375 \\
\hline Number blood gases & $6.0(3.5-6.3)$ & $4.0(4.0-7.0)$ & 0.500 \\
\hline \multicolumn{4}{|l|}{ Day 4} \\
\hline Highest $\mathrm{PCO}_{2} \mathrm{kPa}$ & $6.4(5.9-6.8)$ & $6.2(5.2-6.7)$ & 0.750 \\
\hline Lowest $\mathrm{PCO}_{2} \mathrm{kPa}$ & $4.6(3.8-5.1)$ & $5.0(4.5-5.7)$ & 0.094 \\
\hline Delta $\mathrm{PCO}_{2} \mathrm{kPa}$ & $1.7(0.9-2.8)$ & $0.9(0.3-1.4)$ & 0.156 \\
\hline Number blood gases & $5.0(3.5-6.0)$ & $5.0(4.0-5.0)$ & 0.437 \\
\hline \multicolumn{4}{|l|}{ Day 5} \\
\hline Highest $\mathrm{PCO}_{2} \mathrm{kPa}$ & $7.2(6.4-7.8)$ & $6.3(5.3-8.3)$ & 0.750 \\
\hline Lowest $\mathrm{PCO}_{2} \mathrm{kPa}$ & $5.0(4.9-5.4)$ & $5.1(4.5-5.6)$ & 1.000 \\
\hline Delta $\mathrm{PCO}_{2} \mathrm{kPa}$ & $2.3(1.2-2.8)$ & $0.9(0.5-3.3)$ & 0.750 \\
\hline Number blood gases & $6.0(5.0-7.0)$ & $4.0(3.0-5.0)$ & 0.500 \\
\hline \multicolumn{4}{|l|}{ Day 6} \\
\hline Highest $\mathrm{PCO}_{2} \mathrm{kPa}$ & $7.0(6.5-8.1)$ & $7.7(6.1-7.8)$ & 0.500 \\
\hline Lowest $\mathrm{PCO}_{2} \mathrm{kPa}$ & $5.6(4.9-6.6)$ & $5.6(5.4-6.1)$ & 1.000 \\
\hline Delta $\mathrm{PCO}_{2} \mathrm{kPa}$ & $2.1(0.7-2.7)$ & $1.7(0.7-2.0)$ & 0.500 \\
\hline Number blood gases & $5.0(3.0-6.0)$ & $6.0(4.0-8.0)$ & 1.000 \\
\hline \multicolumn{4}{|l|}{ Day 7} \\
\hline Highest $\mathrm{PCO}_{2} \mathrm{kPa}$ & $7.7(7.4-8.0)$ & $7.5(5.9-8.3)$ & 0.750 \\
\hline Lowest $\mathrm{PCO}_{2} \mathrm{kPa}$ & $5.9(5.5-6.3)$ & $6.1(4.6-6.9)$ & 1.000 \\
\hline Delta $\mathrm{PCO}_{2} \mathrm{kPa}$ & $1.7(1.3-2.2)$ & $1.2(0.6-2.3)$ & 1.000 \\
\hline Number blood gases & $5.0(3.8-6.5)$ & $7.0(3.5-8.0)$ & 0.250 \\
\hline
\end{tabular}

$1 \mathrm{kPa}=7.5 \mathrm{mmHg}$

This may, therefore, affect how they interpret its accuracy and hence their willingness to reduce the number of blood gases taken to monitor $\mathrm{PCO}_{2}$. We have recently described end -tidal $\mathrm{CO}_{2}$ is strongly correlated with $\mathrm{PCO}_{2}$ and the two methods only diverge, as expected, with increasing severity of the underlying lung pathology [17].

Our study has strengths and some limitations. The noninvasive microstream sidestream capnograph device used in the present study has been previously validated against mainstream capnography [17]. We included preterm and term infants who required ventilation for a wide range of pathologies and hence results from this study can be generalisable to other medical and surgical tertiary neonatal intensive care units. We feel our sample size was appropriate, as with a standard deviation for carbon dioxide of $14.8 \mathrm{mmHg}$ $(1.97 \mathrm{kpa})$ in preterm infants [1] our sample of 36 infants in 
each arm (72 infants in total) could detect a difference in carbon dioxide of $11.3 \mathrm{mmHg}(1.51 \mathrm{kPa})$ with $90 \%$ power at $5 \%$ significance level. This difference is smaller than the clinically significant difference in carbon dioxide of $13.0 \mathrm{mmHg}(1.73 \mathrm{kPa})$ reported between preterm infants with or without IVH [1]. This was not a randomised trial, but the two time periods studied, pre and post introduction of $\mathrm{EtCO}_{2}$ monitoring, were consecutive and no other major changes in clinical practice occurred during the study period. A possible limitation of our study was that we routinely used Coles shouldered tubes which have been shown to have minimal or no leak [18] and hence may enable more accurate $\mathrm{EtCO}_{2}$ measurements. Such tubes are not in widespread practice and it would be interesting to assess if the type of endotracheal tube does influence the accuracy of $\mathrm{EtCO}_{2}$ monitoring

In conclusion, we have demonstrated that the presence of continuous end-tidal capnography monitoring in ventilated newborns was associated with a reduction in the highest level and the magnitude of difference in $\mathrm{CO}_{2}$ levels within the first day after birth.

\section{Data availability}

\section{Data available upon request.}

Acknowledgements The research was supported by the National Institute for Health Research (NIHR) Biomedical Research Centre based at Guy's and St Thomas' NHS Foundation Trust and King's College London. The views expressed are those of the author(s) and not necessarily those of the NHS, the NIHR or the Department of Health. Professor Greenough is currently receiving a non-conditional educational grant from SLE.

Author contributions AG and TD designed the study, EW, NO'R, and AW collected the data, AG, TD and EW analysed the data, EW wrote the first draft of the manuscript and all authors approved the final manuscript. Professor Greenough confirms that she has had full access to the data in the study and final responsibility for the decision to submit for publication.

\section{Compliance with ethical standards}

Conflict of interest Specialised Laboratory Equipment (SLE) provided the capnography devices. Professor Greenough is currently receiving a non-conditional educational grant from SLE.

Ethics approval and consent to participate Ethical approval was given by the London (Camden \& King's Cross) Research Ethics Committee. Written, informed consent was given by parents for their infants to take part in the study.

Consent for publication Yes, for publication of anonymised results.

Publisher's note Springer Nature remains neutral with regard to jurisdictional claims in published maps and institutional affiliations.
Open Access This article is licensed under a Creative Commons Attribution 4.0 International License, which permits use, sharing, adaptation, distribution and reproduction in any medium or format, as long as you give appropriate credit to the original author(s) and the source, provide a link to the Creative Commons license, and indicate if changes were made. The images or other third party material in this article are included in the article's Creative Commons license, unless indicated otherwise in a credit line to the material. If material is not included in the article's Creative Commons license and your intended use is not permitted by statutory regulation or exceeds the permitted use, you will need to obtain permission directly from the copyright holder. To view a copy of this license, visit http://creativecommons. org/licenses/by/4.0/.

\section{References}

1. Fabres J, Carlo WA, Philips V, Howard G, Ambalavanan N. Both extremes of arterial carbon dioxide pressure and the magnitude of fluctuations in arterial carbon dioxide pressure are associated with severe intraventricular haemorrhage in preterm infants. Pediatrics. 2007;119:299-305.

2. Okumura A, Hayakawa F, Kato T, Itomi K, Maruyama K, Ishihara $\mathrm{N}$, et al. Hypocarbia in preterm infants with periventricular leukomalacia: the relation between hypocarbia and mechanical ventilation. Pediatrics. 2001;107:469-75.

3. Hansen G, Al Shafouri N, Narvey M, Vallance JK, Srinivasan G. High blood carbon dioxide variability and adverse outcomes in neonatal hypoxic ischemic encephalopathy. J Matern Fetal Neonatal Med. 2016;29:680-3.

4. Sweet DG, Carnielli V, Greisen G, Hallman M, Ozek E, Te Pas A, et al. European consensus guidelines on the management of respiratory distress syndrome - 2019 Update. Neonatology. 2019;115:432-50.

5. Singh BS, Gilbert U, Singh S, Govindaswami B. Sidestream microstream end tidal carbon dioxide measurements and blood gas correlations in neonatal intensive care unit. Pediatr Pulmonol. 2013;48:250-6.

6. Trevisanuto D, Giuliotto S, Cavallin F, Doglioni N, Toniazzo S, Zanardo V. End-tidal carbon dioxide monitoring in very low birth weight infants: correlation and agreement with arterial carbon dioxide. Pediatr Pulmonol. 2012;47:367-72.

7. Levit OL, Shabanova V, Bizzarro MJ. Umbilical catheterassociated complications in a level IV neonatal intensive care unit. J Perinatol. 2020;40:573-80.

8. Brummelte S, Grunau RE, Chau V, Poskitt KJ, Brant R, Vinall J, et al. Procedural pain and brain development in premature newborns. Ann Neurol. 2012;71:385-96.

9. Walker SM, Franck LS, Fitzgerald M, Myles J, Stocks J, Marlow $\mathrm{N}$. Long-term impact of neonatal intensive care and surgery on somatosensory perception in children born extremely preterm. Pain. 2009;141:79-87.

10. Grunau RE, Oberlander TF, Whitfield MF, Fitzgerald C, Morison SJ, Saul JP. Pain reactivity in former extremely low birth weight infants at corrected age 8 months compared with term born controls. Infant Behav Dev. 2001;24:41-55.

11. Jakacka N, Snarski E, Mekuria S. Prevention of iatrogenic anemia in critical and neonatal care. Adv Clin Exp Med. 2016;25:191-7.

12. Papa F, Rongioletti M, Ventura MD, Di Turi F, Cortesi M, Pasqualetti $\mathrm{P}$, et al. Blood cell counting in neonates: a comparison between a low volume micromethod and the standard laboratory method. Blood Transfus. 2011;9:400-6. 
13. Strauss RG. Transfusion therapy in neonates. Am J Dis Child. 1991;145:904-11.

14. Lemyre B, Sample M, Lacaze-Masmonteil T, Canadian Paediatric Society F, Newborn C. Minimizing blood loss and the need for transfusions in very premature infants. Paediatr Child Health. 2015;20:451-62.

15. Gravenstein JS Capnography. 2nd ed. Cambridge. Cambridge University Press: New York 2011.

16. Chandrasekharan PK, Rawat M, Nair J, Gugino SF, Koenigsknecht C, Swartz DD, et al. Continuous end-tidal carbon dioxide monitoring during resuscitation of asphyxiated term lambs. Neonatology. 2016;109:265-73.

17. Williams E, Dassios T, Greenough A. Assessment of sidestream end-tidal capnography in ventilated infants on the neonatal unit. Pediatr Pulmonol. 2020;55:1468-73.

18. Hird M, Greenough A, Gamsu H. Gas trapping during high frequency positive pressure ventilation using conventional ventilators. Early Hum Dev. 1990;22:51-56.

19. McLain BI, Evans J, Dear PR. Comparison of capillary and arterial blood gas measurements in neonates. Arch Dis Child. 1988;63:743-7.

20. Tamura K, Williams EE, Dassios T, Pahuja A, Hunt KA, Murthy $\mathrm{V}$, et al. End-tidal carbon dioxide levels during resuscitation and carbon dioxide levels in the immediate neonatal period and intraventricular haemorrhage. Eur J Pediatr. 2020;179:555-9.
21. Kaiser JR, Gauss CH, Pont MM, Williams DK. Hypercapnia during the first 3 days of life is associated with severe intraventricular hemorrhage in very low birth weight infants. J Perinatol. 2006;26:279-85.

22. Specialist neonatal respiratory care for babies born preterm. National Institute for Health and Care Excellence: clinical guidelines. London 2019.

23. Kugelman A, Golan A, Riskin A, Shoris I, Ronen M, Qumqam N, et al. Impact of continuous capnography in ventilated neonates: a randomized, multicenter study. J Pediatr. 2016;168:56-61.

24. Rowan CM, Speicher RH, Hedlund T, Ahmed SS, Swigonski NL. Implementation of continuous capnography is associated with a decreased utilization of blood gases. J Clin Med Res. 2015;7: $71-75$.

25. Mukhopadhyay S, Maurer R, Puopolo KM. Neonatal transcutaneous carbon dioxide monitoring-effect on clinical management and outcomes. Respir Care. 2016;61:90-97.

26. Cook TM, Kelly FE, Foy K, Mew E, Bower J, Marden B, et al. The PIC-NIC survey: capnography and neonatal intensive care - a reply. Anaesthesia. 2019;74:118-20.

27. Schmalisch G. Current methodological and technical limitations of time and volumetric capnography in newborns. Biomed Eng Online. 2016;15:104. 